Volume 7, No. 12 December 2019

International Journal of Emerging Trends in Engineering Research

Available Online at http://www.warse.org/IJETER/static/pdf/file/ijeter207122019.pdf

https://doi.org/10.30534/ijeter/2019/207122019

\title{
Monitoring System of Graduate Employment as A Factor of Improving the Efficiency of University Educational Activities
}

\author{
Oleg Victorovich Ovchinkin, Alexey Ivanovich Pykhtin², Lyubov Victorovna Shirokova ${ }^{3}$ \\ ${ }^{1}$ Southwest State University, Kursk, Russia \\ ${ }^{2}$ Southwest State University, Kursk, Russia \\ ${ }^{3}$ Southwest State University, Kursk, Russia
}

\begin{abstract}
At present, the efficiency of universities in general and the progress of graduate employment in particular is given a greater attention. To meet the criteria of graduate employment in the framework of monitoring the efficiency of higher education institutions of Russia's Ministry of Education and Science, universities create their own software systems for collecting, processing and storing information on graduate employment and modify the organizational structure to collect information on employment taking into account employment data according to the Pension Fund of the Russian Federation. Southwest State University has been developing and implementing a multi-user client-server system based on 1C: Enterprise 8.3 technology platform since 2012. There have been proposed IDEF0 functional models and the infological ER model of preliminary gathering of information about graduate potential employment and current monitoring of employment distribution channels. The optimal source of data for internal monitoring of graduate employment is the information necessarily transmitted by universities to the state information system "Federal register of educational certificates." As a result, the introduction of this system made it possible to increase the efficiency of collecting information about the current status of graduates, their employment and career development,the speed of information processing for building internal and external statistical reporting, posting information on the employment and graduates' place of work on the official website of the university.
\end{abstract}

Key words: efficiency, university, monitoring, software, employment

\section{INTRODUCTION}

One of the most important criteria for the efficiency of educational activities of universities is graduate employment. Thus, the index "Share of graduates employed during the calendar year following the year of graduation in the total number of graduates of an educational organization who trained in the main educational programs of higher education" is taken into account in the monitoring of higher education organizations' efficiency. The monitoring is held annually by the Ministry of Education and Science of Russia. The calculation of this index is based on data processing from two independent sources: the Pension Fund of the Russian Federation and the Federal register of educational certificates. All educational institutions must supply the Federal register of educational certificates with updated information on the issued certificates every 60 days. Additionally, according to the results of the survey, the Ministry of Education and Science of Russia created the Internet-portal "Monitoring of graduate employment" (graduate.edu.ru), which accumulates the currently processed data on employment and average wages of 20132015 graduates in 2014-2016, respectively; the Internetportal is preparing 2016 graduate data (and their employment for 2017). The portal allows one to get statistical information on Russia as a whole, on region, individual universities, training areas (specialties), and also allows you to assess the internal Russian migration of graduates. It should be noted that the percentage of employment or other similar characteristics are analyzed in the formation of various national and international rankings.

The problem of models, algorithms and software development for forecasting the main indicators of universities' efficiency has been considered in a number of scientific papers [1, 2]. They have shown that the information systems (both commercial and proprietary) used in most universities, as a rule, do not allow to calculate all the forecast values of efficiency indicators. Although, some of them are designed to intellectualize the management of changes in the activities of a university [3, 4,5]. At the same time, the issues of monitoring the employment of graduates, the problem of calculating the employment index used by the Ministry of Education and Science of Russia (data on employment come from the Pension Fund of Russia, which has no information about the contributions of security agencies and similar agencies' officers; recruits for military service, those being on maternity leave, employed or continuing their education abroadare not considered) and creation of appropriate infrastructure in universities are 
being given more attention $[6,7,8]$. At the same time, a number of researchers emphasize the importance of employment share index for the overall efficiency of educational activities of universities [9].

\section{PURPOSE STATEMENT}

This work focuses exclusively on the procedure of monitoring the employment of university graduates, relevant technical means and their role in improving the efficiency of a university. Beyond the study there are no less important issues about a set of measures aimed at the employment of graduates in general: the conclusion of long-term cooperation agreements with potential employers, modernization of educational programs for the needs of large companies, the system of practical trainings, career guidance and career counseling of students, the development of their recruiting competencies and professional adaptation. The process of tracking the employment status of students is important both for the timely provision of accurate external and internal statistical reporting, and for the rapid correction of local "failures" in the employment of graduates.

\section{STUDY MATERIAL AND METHODS}

The research methods used in the study are as follows: system approach, methodology of functional modeling of IDEF0, design theory of databases. Materials for research have been received on the basis of activities of graduate employment and IT department center of FSBEI of Higher Education "Southwest State University" (further as the text goes - SWSU) in 2012-2018 [10, 11, 12].

\section{RESEARCH RESULTS AND DISCUSSION}

The most accurate source of input data for the analysis of graduate employment is the electronic information and educational environment of the university, or namely its subsystem which provides unloading of data on the issued certificates of higher or secondary vocational education in

the Federal register of educational certificates. The university is obliged to provide full correctness and timeliness of information about graduates in the Federal register of educational certificates (surname, name, patronymic name, citizenship, date of birth, details of the issued certificate of education, form of training, source of funding for the training, educational program). These data are taken into account not only by the Ministry of Education and Science of Russia to assess the effectiveness of employment, but also by regulatory authorities (for example, Rosobrnadzor, which stands for Federal Education and Science Supervision Service) during inspections of compliance with the Russian legislation and other organizations, as well as for verification of diplomas for authenticity when entering employment.

It should be noted that in the Kursk region, the regional education management authority annually collects preliminary information (forecast) on the potential distribution of graduates through employment channels before graduation. Accordingly, at this time information about the actual graduation year is not available, and the only relatively reliable source of information about future employment is a survey of graduate students and verification of this information at the level of departments, faculties and the graduate employment center. A functional model of this process, designed with the IDEF0 methodology with the help of the Ramus Educational program, is shown in Figure 1.

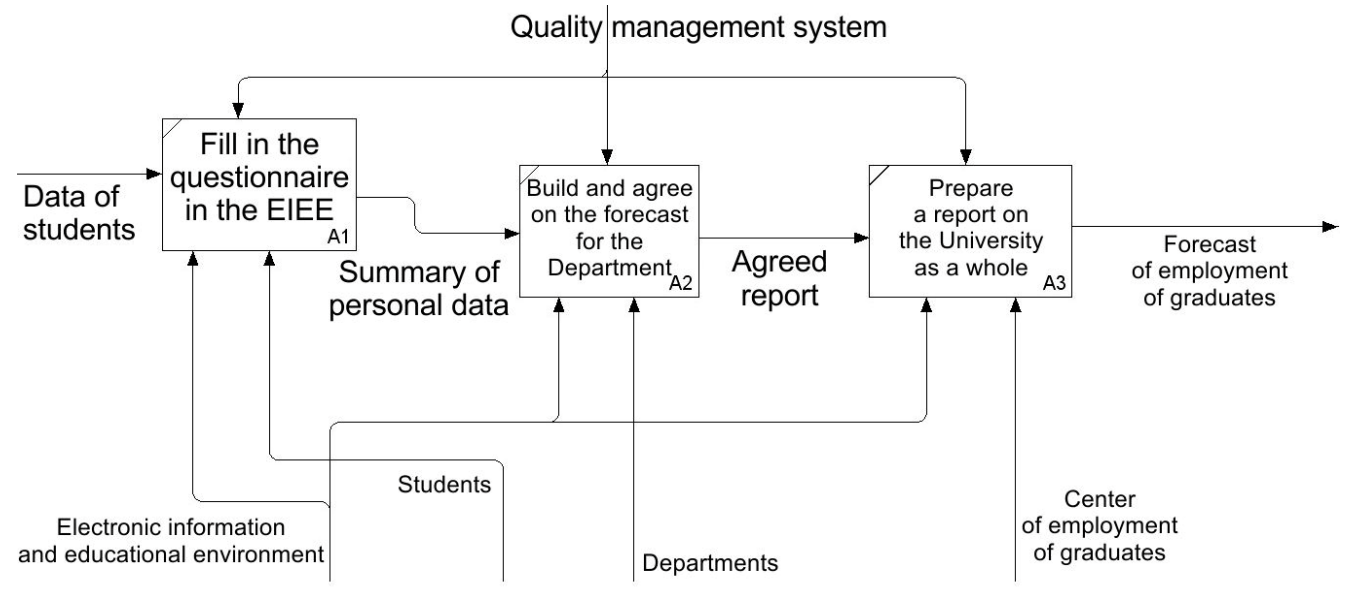

Figure 1: IDEF0 - model of preliminary monitoring of graduates' distribution through employment channels

Preliminary monitoring makes it possible to identify the problem areas of employment for the current graduation year in advance and take the necessary organizational measures. For example, explanatory work should be organized with graduates planning to continue their education or employment abroad, with those being on maternity leave, people going to do conscription or contract military service. They should be offered options 
for part-time employment in the Russian Federation, including remote work specific for their areas of activity, the results of which will be reflected in contributions to the Pension Fund of Russia within a year after graduation.

The functional model of keeping track of the current employment of graduates which provides quarterly reports and assesses the implementation of the criterion of monitoring the efficiency of universities is presented in Figure 2. The main essentials of the infological ER-model of the process of monitoring the graduate employment designed in the Dia program are presented in the fragment in Figure 3. The software for the monitoring system has been implemented using the technological platform " $1 \mathrm{C}$ : Enterprise 8.3" as a configuration of its own design.

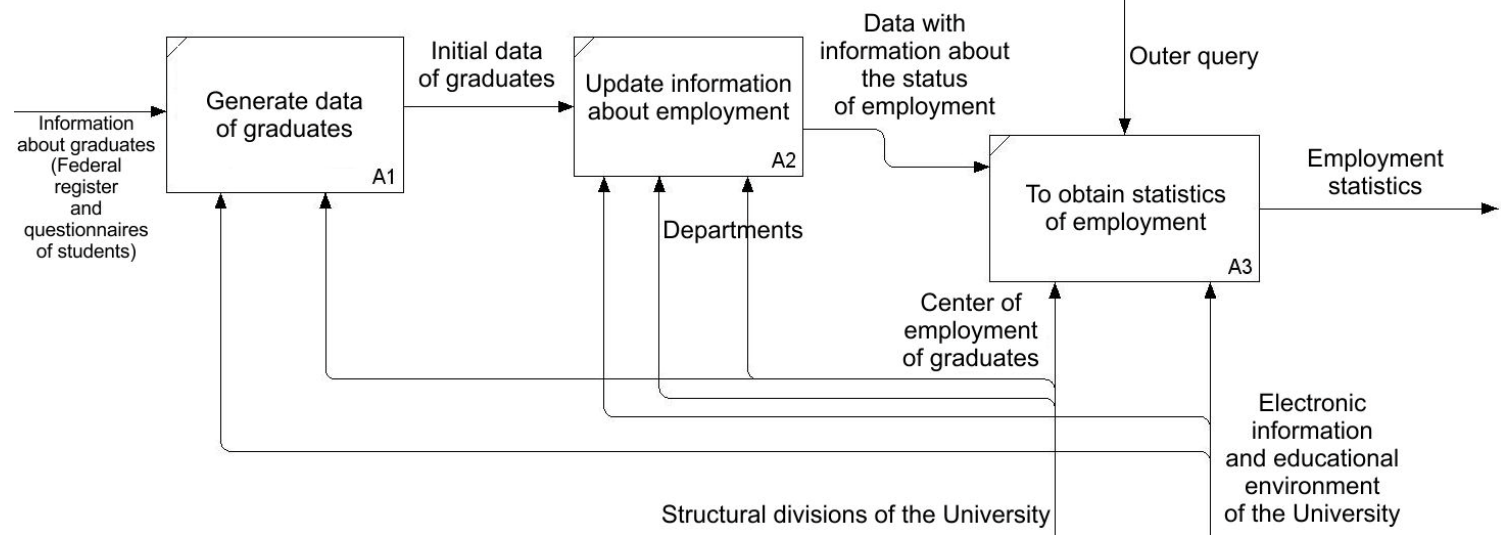

Figure 2: IDEF0 - model of the process of monitoring the current employment of graduates

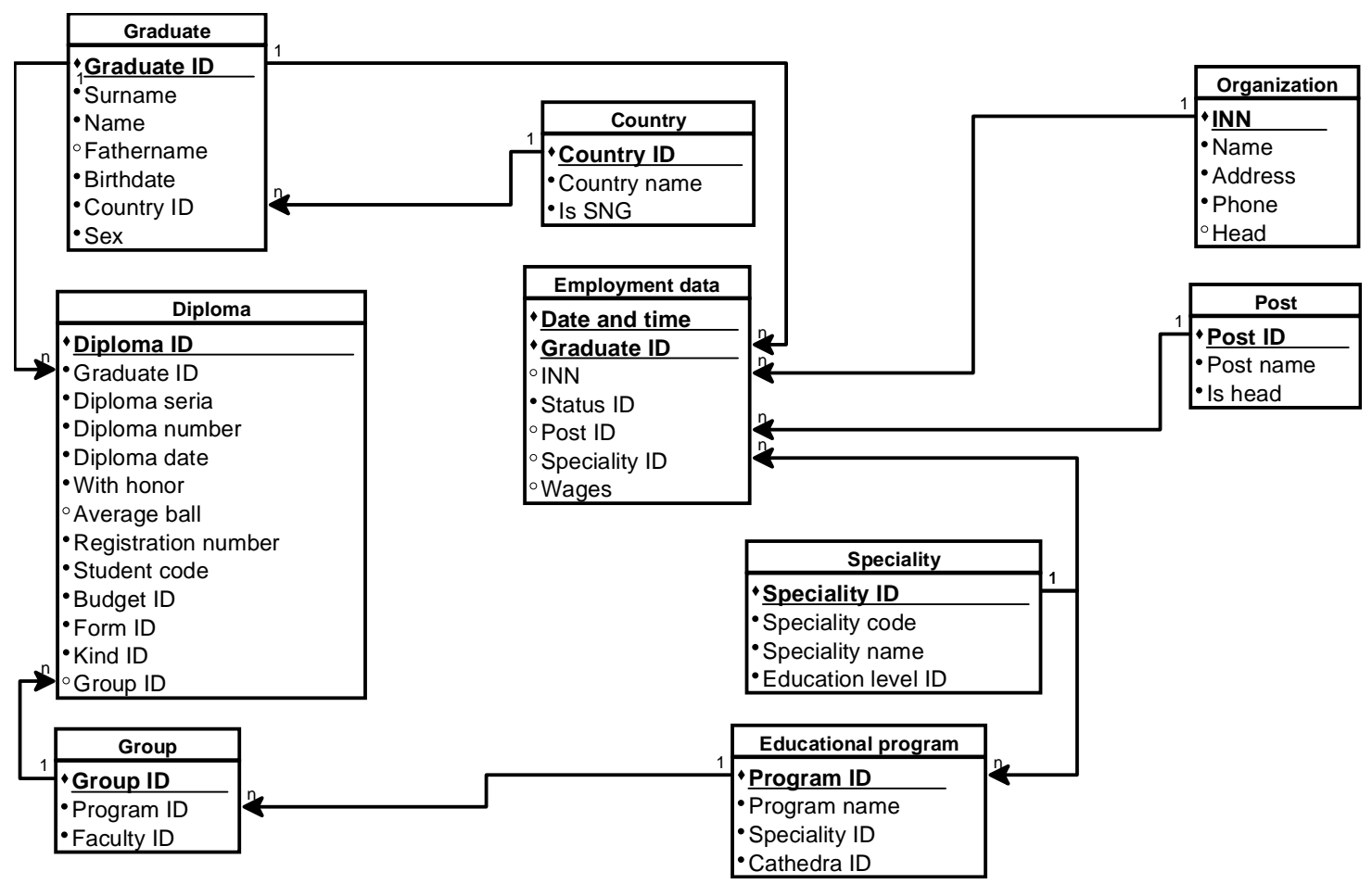

Figure 3: Fragment of ER-model of the process of monitoring the employment of graduates

After entering data transferred by the university to the Federal register of educational certificates into the system, departments, faculties and the employment center are able to add information about the current employment status of each graduate ("at work", "at work abroad", "serves in the army", "continues education", etc.) in multi-user client- server mode indicating the place of employment, position and their compliance with the profession. The history of status changes is stored and allows you to track the personal career trajectory of each graduate. One should note that the architecture of platform "1C: Enterprise 8.3" enables secure access to employment data on the local 
network of the university through the Web-interface without the need to install and update the client software of each individual user.

The system makes it possible to create general external reports (for example, the data for VPO-1 form (form with information about an educational institution which implements higher education programs), the number and percentage of graduates of a university, faculty, training areas or separate groups in terms of status) as well as specific internal reports, for example, with the selection of candidates who have 2 higher educations in specified fields and who served in the army, of individuals with leadership experience, etc., which allows you to respond to specific needs of employers. The system software program can

Table 1: Current properties of SWSU graduate employment monitoring system in comparison with the previous system

\begin{tabular}{|l|r|r|}
\hline \multicolumn{1}{|c|}{ Property } & Pre-existing system & Created system \\
\hline Number of analyzed graduates in the system. & 1500 & 12305 \\
\hline Number of analyzed diplomas of graduates in the system. & 0 & 18694 \\
\hline $\begin{array}{l}\text { The amount of information about the places of graduate employment posted and } \\
\text { being continuously updated on the official website of the university }\end{array}$ & 0 \\
\hline Average time of searching information on employment of a graduate, min. & 10 \\
\hline $\begin{array}{l}\text { Average time of formation and publication of one report for the section of the site } \\
\text { "Information about the educational organization", min. }\end{array}$ & 240 \\
\hline The option of specific selection of graduates through multiple statuses & 5 \\
\hline $\begin{array}{l}\text { Average time of data collection on the current employment status of one year } \\
\text { graduates, days }\end{array}$ & Nil & 10 \\
\hline
\end{tabular}

\section{CONCLUSION}

Thus, the paper describes the structure of monitoring system of graduate employment in the FSBEI of Higher Education "Southwest State University", its functional and ER-model. It has been shown that the introduction of this system has increased the efficiency of collecting information about the current status of graduate employment at least five-fold. Speed of data processing for external and internal statistical reporting, which meets the requirements of Rosobrnadzor for placement of information about places of employment on the official website of a university on the Internet, has increased by 48 times. While considering efficiency as "the relative effectiveness of the process, defined as the ratio of result to costs which caused or contributed to its obtainment", we can conclude that with the remaining current costs for maintenance of the monitoring system of graduate employment, introduction of new tools has increased the efficiency of the whole system, enhancing the effectiveness of the process. generate information about the places of graduates' employment according to the format approved in the guidelines of Rosobrnadzor, and without further processing post them on the official website of the university in the mandatory section "Information about the educational organization", which greatly simplifies this time-consuming procedure that should generally be performed within 10 days since the moment of information changes.

The current properties of the new SWSU computer software and organizational system for monitoring the graduate employment in comparison with the previous one are shown in Table 1.

\section{ACKNOWLEDGEMENT}

The work has been carried out within the grant of President of the Russian Federation for state support of young Russian scientists - candidates of sciences No.MK968.2018.8.

\section{REFERENCES}

1. N.V. Jandybaeva. Modeling and Forecasting Performance Indicators for Educational Activites of Higher Educational Institution, Mordovia University Bulletin, No. 1, pp. 120-136, 2018. https://doi.org/10.15507/0236-2910.028.201801.120-136

2. N.V. Jandybaeva and V.A. Kushnikov. Mathematical models, algorithms and complexes of programs for monitoring the efficiency of the educational activities of the higher school, Control Sciences, No. 1, pp. 53-62, 2015.

3. Ya.P. Bondarev and Ya.E. Lvovich. Intellectualization of change activities university based on monitoring - rating information, Modern problems of science and education, No. 3, pp. 13, 2013.

4. J. Zheng, J. Tang and J. Gao. Construction of Graduate Employment Service System Based on Public Information Platform, AASRI Procedia, Vol. 1, pp. 410-415, 2012. 
https://doi.org/10.1016/j.aasri.2012.06.064

5. G. A. Bulatova. Monitoring and evaluation of graduates employment, Economics Profession Business, No. 4, pp. 18-23, 2017.

6. A.N. Maloletko, N.E. Maloletko and T.I. Vorobyeva. Problems of development of formation of monitoring system for employment of graduates of Russian universities, Alma Mater (Higher School Herald), No. 8, pp. 63-68, 2015.

7. I.I. Kleshnina and T.G. Makusheva. Methods of organization of monitoring of employment of graduates in higher educational institutions, Innovation science, No. 6, pp. 124, 2017.

8. M. M. Eliophotou, N. Pashourtidou, A. Polycarpou and P. Pashardes. Students' expectations about earnings and employment and the experience of recent university graduates: Evidence from Cyprus, International Journal of Educational Development, No. 6, Vol. 32, pp. 805-813, 2012. https://doi.org/10.1016/j.ijedudev.2011.11.011

9. Y.E. Lvovich, I.L. Kashirina and A.N. Schwindt. Network-based simulation of the results monitoring evaluation of activity of universities, Modeling, Optimization and Information Technology, No. 4, pp. 31, 2017.

10. L. Shirokova. Graduates employment in the Russian federation higher education system: condition, prospects, projections, in SGEM International Multidisciplinary Scientific Conference on Social Sciences and Arts 2018. Conference proceedings. Book 3.4: Education and educational research, Sofia, 2018, pp. 375-383.

11. A.I. Pykhtin and O.V. Ovchinkin, Increasing indicators of effectiveness of the higher educational institution by regulation of the threshold scores of the unified state examination, Journal of Applied Engineering Science, No. 17(2), pp. 198-202, 2019. https://doi.org/10.5937/jaes17-21684

12. A.I. Pykhtin, O.V. Ovchinkin and I.A. Zeveleva, The algorithm for a single competition for admission to higher education programmes, International Journal of Applied Engineering Research, No. 10(7), pp. 18417-18434, 2015. 